\title{
Utilizing the "teach-back" method to improve surgical informed consent and shared decision-making: a review
}

\author{
Kevin D. Seely ${ }^{1 *}$ (D) Jordan A. Higgs ${ }^{1}\left(\mathbb{B}\right.$ and Andrew Nigh ${ }^{2}$ (D)
}

\begin{abstract}
The teach-back method is a valuable communication tool that can be employed to improve patient safety and shared decision-making. Its utility in patient care has been studied extensively in many areas of clinical medicine. However, the literature on the use of teach-back in surgical patient education and informed consent is limited. Additionally, there is some ambiguity about the functional definition and performance of the teach-back method in the literature, consequently rendering this valuable tool an enigma. This review examines the current standards and ethics of preoperative informed consent and provides a concise, actionable definition of teach-back. The manner in which teach-back has been implemented in medicine and surgery is then examined in detail. Studies analyzing the use of teach-back in medicine have demonstrated its effectiveness and benefit to patient care. Further study on the use of teach-back to improve preoperative informed consent is supported by the few preliminary trials showing a positive effect after implementing the teach-back method in critical patient interactions.
\end{abstract}

Keywords: Surgery, Preoperative education, Informed consent, Teach-back method, Shared decision-making

\section{Introduction}

Patient autonomy, shared decision-making, and informed consent are foundational components of ethical patient care [1]. Modern best practices concerning patient education and shared decision-making place responsibility on patients to participate in the healthcare-related decision-making process [2]. Therefore, practical interpersonal strategies are needed to support patients' understanding of complex health information that enables them to make informed, high-consequence decisions. The teach-back method has been shown to aid in the shared-decision making process and improve health literacy and outcomes [3]. However, despite the proven benefits in patient education and outcomes in many areas

*Correspondence: Kevin.seely@rvu.edu

${ }^{1}$ College of Osteopathic Medicine, Rocky Vista University, Ivins, UT 84738, USA

Full list of author information is available at the end of the article of medicine, the literature on teach-back in the surgical literature is limited.

This review examines the literature and key findings pertaining to the teach-back method in medicine that can be implemented in surgical practice and pre-operative education. Because there is some ambiguity about the functional definition and performance of the teach-back method in the literature, a concise and actionable definition of teach-back is established. The evidence regarding the use of teach-back in medicine, including how teachback is delivered, the effectiveness of teach-back across different healthcare settings and populations, and how teach-back might be applied to preoperative informed consent, is examined.

Communication is crucial to the delivery of patientcentered healthcare [4]. With the transition from a system and culture of medical paternalism to one of shared decision-making and patient autonomy has come the unprecedented importance of effective communication. original author(s) and the source, provide a link to the Creative Commons licence, and indicate if changes were made. The images or other third party material in this article are included in the article's Creative Commons licence, unless indicated otherwise in a credit line to the material. If material is not included in the article's Creative Commons licence and your intended use is not permitted by statutory regulation or exceeds the permitted use, you will need to obtain permission directly from the copyright holder. To view a copy of this licence, visit http://creativecommons.org/licenses/by/4.0/. The Creative Commons Public Domain Dedication waiver (http://creativeco mmons.org/publicdomain/zero/1.0/) applies to the data made available in this article, unless otherwise stated in a credit line to the data. 
Adverse health outcomes, compromised safety, and increased economic burden are attributable to communication gaps and the breakdown of physician-patient relationships $[4,5]$. This is particularly true when considering pre-operative education and informed consent. Many factors contribute to effective communication, including tone, subject matter, patient anxiety, fear levels, patient expectations, physician workloads, fear of litigation, and concern of physical or verbal abuse [6]. The ultimate goals of physician-patient communication include mutual understanding, establishing a rapport, facilitating the exchange of information, and including patients in decision making [7].

Physicians have a legal and ethical responsibility to provide patients with information so that they can process the information and make appropriate decisions during the informed consent process [8]. An educated patient benefits the physician, both in terms of cooperation in the planned intervention and in reducing acrimony if complications arise [8]. The extent to which surgeons choose to educate patients preoperatively is inconsistent with no established norm. Notwithstanding the wide variety in delivery in terms of time length, place, and pace, informed consent is ethically and legally required prior to invasive medical and surgical procedures. At the very least, providers are legally required to provide consent forms to the patient, which they must sign prior to surgery. However, it is becoming increasingly evident that basic consent forms provide insufficient information to adequately guide the general population in decisionmaking. Manta et al. in a 2021 study on patient perspectives about informed consent, showed that consent forms are too complex to achieve appropriate patient comprehension [9]. In a 2014 letter to the editor, Bracaglia et al. argued that a conventional informed consent form does not achieve effective communication or comprehensive knowledge on the part of the patient at the time of signing. Furthermore, they assert that a patient's signed permission does not assure that the patient fully comprehends its contents. They conclude that in a medical culture pursuant to increasing patient autonomy and self-determination, the first step toward a solution would be to assess the patients' degree of understanding of the information presented [10].

Informed consent occurs when patient-clinician communication results in a patient's authorization to undergo a specific medical intervention [11]. The process should ideally help ensure both adequate disclosure on the part of the physician and sufficient comprehension on the part of the patient [12]. Consent is valid only when the patient has the capacity to consent, has discussed and understood all relevant information, consents voluntarily, and communicates their decision [13]. The process of informed consent can be described as having five core components: (1) assessment of decision-making capacity, (2) discussion of pertinent information, (3) assessing comprehension, (4) ensuring voluntary consent through collaborative deliberation, (5) formally obtaining consent with correct documentation and signature [14]. Teachback has been proposed as an efficient way to improve the second and third components, assessing comprehension and aiding in the shared decision-making process (Fig. 1).

\section{Teach-back method}

The teach-back method, a dynamic, interactive process, was created to improve the communication between provider and patient, allowing the physician to identify and resolve any misunderstandings in real-time, thus improving the comprehension of information $[15,16]$. This technique may reveal cognitive, cultural, language, or health literacy barriers that increase the risk of miscommunication or unintended messaging [17]. As there is no standardized operational definition of feedback, the exact process used throughout the medical system may vary [18].

Teach-back consists of multiple steps involving the clinician introducing new information, assessing the recall of the patient by asking them to repeat what they understood, and by clarifying and tailoring the information to the patient's level of understanding, the clinician will then reassess the patient's understanding. It has been suggested that this cycle be repeated as many times as necessary for comprehension by the patient [19-21].

The operative definition used in this paper consists of providing new information with several checks for recall; however, the initial check for recall must be preceded by a "framing statement." The purpose of this statement is to place the focus of the conversation on effective communication between the patient and provider and may serve to reduce stigma experienced by the patient $[18,22]$. An example of a framing statement would be "I want to make sure I explained correctly." The framing statement should effectively place the focus of the teach-back process on the communication effectiveness of the physician and not the patient's ability to understand. If during the process of teach-back, the patient successfully verbalizes adequate understanding of the subject matter, the process is complete (Fig. 2).

Despite the teach-back process having been shown to initiate more desirable outcomes for patients regardless of differences in age and education levels, it may not be utilized often enough in medical care [23]. Multiple studies have analyzed factors such as the use of medical jargon, assessment of patient understanding, and use of teach-back. These studies have shown that residents 


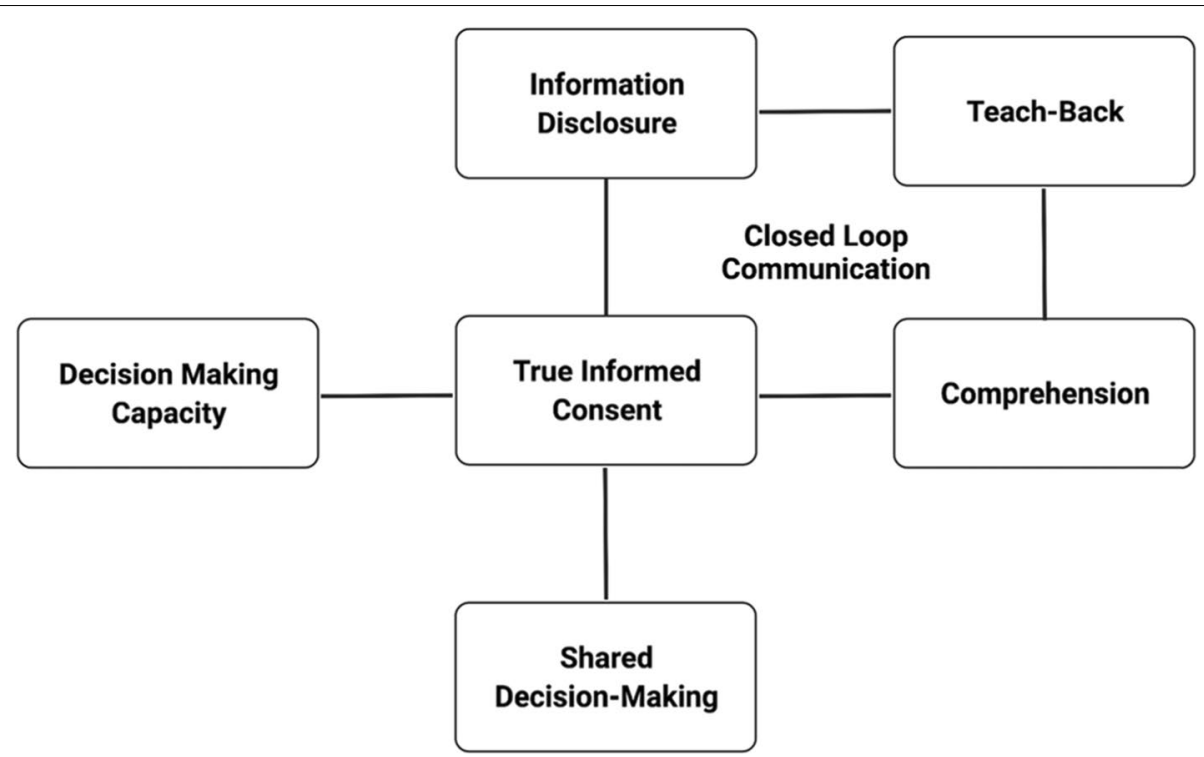

Fig. 1 Teach-back adds a closed-loop communication aspect to the informed consent process. It facilitates enhanced informed consent and aids in the shared decision-making process

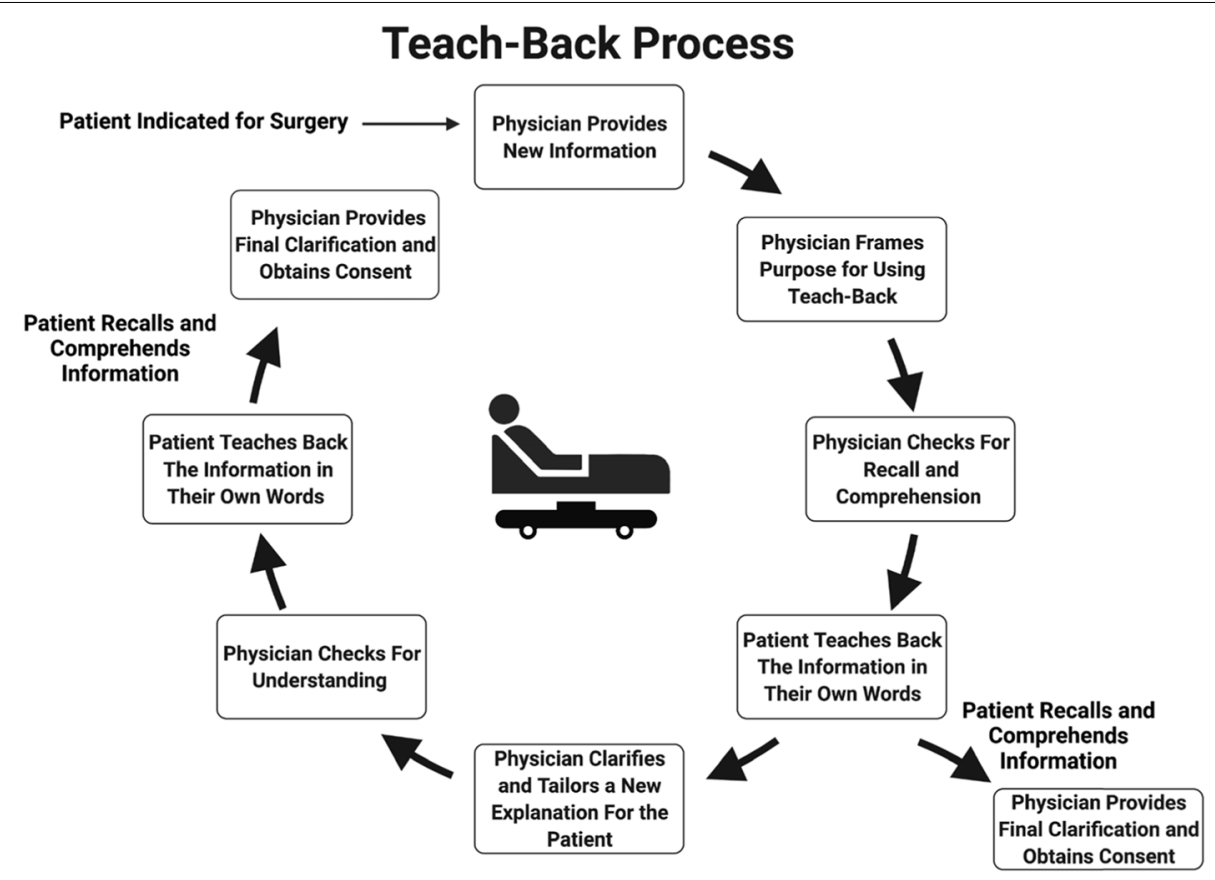

Fig. 2 Teach-back is a dynamic, interactive, and patient-centered process that may require multiple repeated sequential explanations, checks for comprehension, and clarifications

who are asked to evaluate the utilization of their communication with patients, tend to overestimate the effectiveness of their communication [24, 25]. The variance of communication effectiveness between provider and patient may contribute to problems that arise at the time of a patient's care. Issues such as insufficient comprehension of one's own medical diagnosis, procedural complications, or post-op care, may be tied to issues of physician communication. 


\section{Ethical basis of informed consent}

Truly informed consent protects the patient's right to self-determination [8]. Respect for autonomy in the form of freedom to decide what happens to one's own body is the key ethical rationale for gaining informed permission from patients. Included in this definition is the ability to accept or reject therapies that clinicians deem medically justified. In some cases, the need for consent may be outweighed by the need for urgent intervention. In emergency situations, the patient may be less capable of receiving, interpreting, or communicating information [26]. When possible, the medical facts of the case should be explained to the patient and with the patient's permission to the family. In the case of language barriers between patient and provider, a translator trained in medical terminology is often required to transmit accurate information [27]. The ethics of surrogate decisionmaking is outside of the scope of this paper, and the authors direct the reader to a recent review written by Kim et al. addressing current issues surrounding surrogate decision-making and informed consent [28].

\section{Evolution of informed consent before surgery over time}

Informed consent has evolved slowly. Early documentation of the patient-physician relationship was from the pages of the ancient Greek Corpus Hippocraticum. Although these papers did not describe the physicianpatient relationship that we know today, they were among the first to describe the principles of beneficence and nonmaleficence, ethical standards for all physicians. The idea that physicians have a moral and ethical contract to the patients who enter into their care has evolved through the ideas of physicians such as French surgeon Henri de Mondeville, moralist John Gregory, Declaration of Independence signer Benjamin Rush, and Thomas Percival in his treatise on medical ethics [29]. These contributions led to the eventual publication of the "American Medical Association (AMA). Medical Ethics" in 1847, which outlined the honorable behavior of physicians. However, it was not until Worthington Hooker published a commentary on the AMA medical ethics code denouncing lying to patients, performing unnecessary procedures, and observing "the science of patient getting, to the neglect, to some extent, at least, of the science of patient curing" that honorable treatment of patients was emphasized [30].

Events of the early twentieth century laid the foundation for informed consent that we currently recognize. Informed consent developed through the contributions of many individuals with the outcome of increasing the capacity of physicians to serve the needs of their patients. It has enabled patients greater control over their own care and access to information that will allow them to make well-advised healthcare decisions. This stepwise process was developed through trial and error based on principles of battery and negligence [29]. Precedents of judicial cases led to the development of the modern standard of informed consent. Summaries of these key cases and events are provided in Table 1.

\section{Current standards and requirements}

Assessment of decision-making capacity is based on a determination that the patient is competent, meaning, the patient is able to comprehend their medical problems

Table 1 Legal developments in informed consent in the twentieth century

\begin{tabular}{|c|c|c|c|}
\hline Date & Case & Significance & References \\
\hline 1905 & Mohr v. Williams & $\begin{array}{l}\text { When entering into a contract, the physician can operate to the extent of the con- } \\
\text { sent given, but no further. }\end{array}$ & {$[31]$} \\
\hline 1906 & Pratt v. Davis & $\begin{array}{l}\text { Limited implied consent to emergencies or when the patient knows the conse- } \\
\text { quences of allowing the physician to exercise professional judgment }\end{array}$ & {$[32]$} \\
\hline 1913 & Rolater v. Strain & Strengthened the patient's control over their care & {$[33]$} \\
\hline 1914 & Schloendorff v. Society of NY Hospital & $\begin{array}{l}\text { Competent individuals have a right to decide what will be done to their bodies. } \\
\text { Performing surgery without a patient's consent is assault, and the surgeon may be } \\
\text { held liable }\end{array}$ & {$[34]$} \\
\hline 1957 & Salgo v. Stanford & $\begin{array}{l}\text { Physicians must disclose facts necessary to make an intelligent consent for the } \\
\text { proposed treatment }\end{array}$ & {$[35]$} \\
\hline 1960 & Natanson v. Kline & $\begin{array}{l}\text { If injury results from a known risk that is not disclosed to the patient, the physician } \\
\text { may be liable }\end{array}$ & {$[36]$} \\
\hline 1972 & Cobbs v. Grant and Wilkinson v. Vesey & $\begin{array}{l}\text { Whether a patient should proceed with therapy requires reference to the values of } \\
\text { that patient and thus are not exclusively medical determinations }\end{array}$ & {$[37,38]$} \\
\hline 1973 & Legislation & Patient's Bill of Rights published & \\
\hline 1975-1977 & Legislation & 25 states enacted informed consent laws to decrease malpractice suits. & \\
\hline 1980 & Truman v. Thomas & Physicians must apprise the patient of the risks of not undergoing treatment & [39] \\
\hline
\end{tabular}


and make decisions for their own health care [40]. When competency has been ascertained, the physician is obligated to present to the patient pertinent information that enables them to make a well-informed decision. Information provided should consist of their diagnosis, proposed treatment or procedure with its accompanying risks and benefits, alternative treatment options with respective risks and benefits, additional procedures that may become necessary during the course of a procedure, and the risks of refusing treatment. Difficulty may arise in evaluating how much information is pertinent to the patient with regards to a patient's health education and background.

Laws in some states detail the information that must be presented for a specific procedure, but ultimately, the depth of the discussion is left to the discretion of the physician $[37,41]$. The physician is also obligated to disclose information truthfully when asked by the patient, including the number of similar procedures performed and success rates. Failure to do so would leave the physician open to allegations of fraud and misrepresentation and "negligent nondisclosure" [42, 43]. Additionally, any financial conflicts of interest, such as an instance of a provider having part ownership of a lab or facility, must be disclosed and as well as any commercial interest in the patient's cells, devices, or techniques [44]. The patient has the ultimate right to be advised about any individuals participating in their care. This includes but is not limited to attendings, residents, or students [45].

Physicians may proceed with the informed consent process in a variety of ways chosen to best address a particular patient's needs. Informed consent can be discussed verbally with the use of educational material or interpreters. Providing the patient with relevant materials is especially beneficial in helping patients retain more information and achieve a better understanding of procedures. Patients additionally feel more involved, have a better sense of their values, and are better able to become more involved in their healthcare [46-48]. Because comprehension of informed consent has been shown to depend on the educational level of the patient [49], physicians may utilize any number of supplemental materials or other interventions to cater to an individual patient's needs.

Because many medical procedures are complicated and often multifaceted, it is critically important for physicians to document the informed consent process. Patients may have difficulty.

remembering all the facts of their procedure, so the discussion must be documented to avoid any misunderstanding or litigation $[50,51]$. The physician in charge of the procedure should take responsibility for ensuring that the informed consent is presented and properly documented $[52,53]$. In the documentation, they should be sure to include what was discussed in the patient visit, who was in attendance, and the other elements of wellinformed consent to ensure a thorough report.

\section{Teach-Back in medicine}

Teach-back has been shown to be a valuable strategy that can improve the safety and quality of health care and improve health literacy [54], which has been adopted in a variety of fields, to varying degrees of consistency. A 2019 study on the use of teach-back by medical residents revealed that residents believe they are using teach-back to confirm patient understanding $60 \%$ of the time when they actually used teach-back only $2.5 \%$ of the time. Following the educational intervention, the residents used teachback $53 \%$ of the time. As a result, was found that teachback language was collaborative and patient-centered, and all but two of 78 patients confirmed their medication and discharge plan after teach-back intervention [24].

Informed consent regarding heart medication instruction is one area in which teach-back has been successfully implemented. White et al. conducted a prospective cohort study in 2013, that involved 276 heart-failure patients over 13 months. Patients were educated and evaluated using the teach-back method in addition to collaborative care planning and patient education. Data on ability to recall educational information while hospitalized and during follow-up, approximately seven days after hospital discharge were collected and compared to readmissions data. Data analysis showed that the teachback method is an effective method used to educate and assess learning and that patients educated longer retained significantly more information than did patients with shorter instruction. The study did not show a correlation between patient knowledge and a decrease in readmission [55]. Another study of the effect of teach-back on knowledge, outcome, readmission, and quality of life in heart-failure patients showed significant improvements in patients' knowledge and performance immediately after teach-back education, although they found that this effect was lessened as time from discharge increased. No correlation between teach-back and decreased frequency of readmission was uncovered [56]. This study also showed a statistically significant increase in patientperceived quality of life through teach-back education in terms of vitality, general health, and social functioning.

One meta-analysis analyzing the use of teach-back in the management of chronic disease found that teach-back showed positive effects in a wide range of healthcare outcomes, including improved disease-specific knowledge, adherence to medication regimens and diet modifications and foot care [21]. Another meta-analysis published in 2017 by Yen et al. came to similar conclusions noting 
that the use of the teach-back method is effective in reinforcing or confirming patient understanding. Additional findings of this analysis showed that none of the studies reported harmful outcomes and that the teach-back method, therefore, can be safely used to increase patient understanding and satisfaction [57].

Teach-back has also been shown to be effective in educating patient home caregivers. A significant increase in recall of the purpose and side-effects of new medications was shown in a 2019 study by Prochnow et al. in which 25 registered nurses and 74 patients with some of their caregivers were observed in instruction sessions and surveyed following the discussion about medication importance, adherence, and side-effects. In a quality improvement project aiming to improve caregivers' confidence in caring for hospice patients and decreasing hospitalizations, a pre-test-post-test model was used to analyze the effectiveness of teach-back in reducing hospitalizations in hospice patients. After the intervention, the teach-back group had zero hospitalizations compared with two hospitalizations for the non-teach-back group. Patient-caregiver "confidence" increased from $58 \%$ to $81 \%$, pre- to post-intervention. These authors concluded that teach-back is a cost-effective teaching methodology that can be implemented by any discipline to improve patientprovider communication and patient outcomes [58].

Teach-back has also been widely studied in oncology. A systematic review conducted by Choi et al. found 246 published articles pertaining to the use of the teach-back method with cancer patients. The study found that teachback interventions promoted positive health outcomes, including increased happiness, decreased uncertainty, better self-efficacy and self-management behavior, lessened symptom experience, diminished distress and anxiety, and improved health literacy among cancer patients. Whether or not these same outcomes translate to the surgical care setting has not been studied extensively [59].

Discharge instructions are one area in which teachback has been found to be particularly effective. Studies of methods to improve discharge instruction and decrease readmission rates have increased in number since a 2011 study that showed patients commonly remained confused about their condition, treatment, and discharge instructions after standard discharge [60]. Another study questioning patient comprehension and recall of discharge instructions showed that the majority of participants demonstrated an unsatisfactory level of comprehension regarding discharge information in at least one domain analyzed and that the majority of those were unaware of their own lack of understanding [61]. A meta-analysis by Oh et al. examined articles using teach-back education to confirm and reinforce patients' comprehension of health-related information. They concluded that discharge directives delivered with the teach-back method resulted in a $45 \%$ reduction in 30-day readmissions. This study did have a high rate of selection bias due to limited trials, but the preliminary data support further inquiry [62].

Slater et al. in their 2017 study, added to the evidence when they showed that the teach-back method had a positive association on retention of discharge instructions in the emergency department regardless of age and education [63]. Despite growing evidence and teach-back being considered by some to be a "key discharge communication practice," a 2021 survey of internal medicine residents revealed that only $17.0 \%$ of respondents reported routinely asking patients to "teach-back" or explain their understanding of the discharge plans. This study concluded that there is a disconnect between what we know to be best practice in discharge communication and what is actually demonstrated [23].

\section{Teach-Back in surgery}

A literature search on teach-back in surgery yields limited results (Table 2). Pre-operative informed consent strategies showing either positive results or no change include written interventions $[49,68]$, audiovisual interventions [69], digital media interventions [70], and combinations of the above interventions [71]. A systematic review and meta-analysis comparing studies of these methods showed that interactive interventions, particularly with feedback or teach-back components, appear superior [64]. The available studies that utilized teach-back in surgical informed consent are summarized in Table 2.

In a cohort of spinal stenosis surgical patients, Kesanen et al. provided routine preoperative education that included a face-to-face discussion with a surgeon and nurse, written material, and a "knowledge test feed-back intervention." Patients were administered a 27-item true or false test, received the results with corrections, then completed an empowering telephone discussion with a nurse based on the patient's existing knowledge. The patient's understanding of risks, benefits, alternatives, and general knowledge about the procedure were assessed and compared with a control group who received only routine preoperative education. The intervention group showed superior performance on assessments at admission, discharge, and six months post-operation [65].

Fink et al., in a 2010 study on teach-back in carotid endarterectomy, laparoscopic cholecystectomy, radical prostatectomy, and total hip arthroplasty preoperative informed consent showed that the total mean comprehension scores for all operations after a 23-26 item questionnaire were $71.4 \%$ for the intervention group versus $68.2 \%$ for the control group. Standard informed consent 
Table 2 Results from trials of verbal discussion with test/feedback or teach-back interventions to improve patient comprehension in informed consent. These studies constitute the available literature on teach-back in surgical informed consent. Adapted from Glaser et al. 2020 [64]

\begin{tabular}{|c|c|c|c|}
\hline Procedure & Intervention & Results & Reference \\
\hline Spinal Stenosis Surgery & $\begin{array}{l}\text { Routine, preoperative education followed by } \\
\text { a "Knowledge Test Feedback Intervention" }\end{array}$ & $\begin{array}{l}\text { Improved performance on knowledge test } \\
\text { at admission, discharge, and at six months } \\
\text { post-operation. }\end{array}$ & {$[65]$} \\
\hline $\begin{array}{l}\text { Carotid endarterectomy, laparoscopic } \\
\text { cholecystectomy, radical prostatectomy, and } \\
\text { total hip arthroplasty }\end{array}$ & $\begin{array}{l}\text { Web-based tool with a knowledge check } \\
\text { and a period for clarification before signing } \\
\text { consent. }\end{array}$ & $\begin{array}{l}\text { Total mean comprehension scores for all } \\
\text { operations were } 71.4 \% \text { intervention vs. } \\
68.2 \% \text { control, } P=0.03 \text { tested immediately } \\
\text { after intervention }\end{array}$ & {$[66]$} \\
\hline Various elective surgeries & $\begin{array}{l}\text { A questionnaire was given immediately } \\
\text { after informed consent with a teach-back } \\
\text { component to assess time for a decision, sat- } \\
\text { isfaction consent, and information provided } \\
\text { about the proposed surgery (e.g., indica- } \\
\text { tions, benefits, risks, and alternatives). }\end{array}$ & $\begin{array}{l}\text { Patients reported high satisfaction with } \\
\text { teach-back during surgical informed con- } \\
\text { sent. Teach-back is not detrimental to the } \\
\text { consent process and may improve informed } \\
\text { consent for surgery. }\end{array}$ & {$[67]$} \\
\hline
\end{tabular}

was delivered using a web-based tool. When participants were ready to sign the consent, a teach-back dialog was initiated that prompted the provider to test the participant on essential information. The provider could then present additional information and instruction depending on the participant's responses. The control group received standard informed consent using the same web-based tool with no additional support [66]. A follow-up to this study conducted by Prochanzka et al. in 2014 showed that surgical patients were highly satisfied with teach-back during the informed consent process, that teach-back did not deter from the process, and that teach-back improves informed consent [67].

\section{Conclusion}

Teach-back is a valuable tool that can be employed to improve patient safety and understanding. It can provide the physician potent insight into the degree to which a patient understands the presented information. and can open a dialogue to resolve misunderstandings about the risks and benefits of a procedure. Unfortunately, the literature on the use of teach-back in the surgical informed consent process is minimal, despite evidence of its significant benefit in many other fields of medicine. However, some quality studies have established a baseline for advancing informed consent using methods such as teach-back. Improved patient knowledge benefits both the patient and the physician and enhances informed consent. Shared-decision making in the informed consent process may be enhanced by implementing teach-back in pre-operative discussions and its use should be further evaluated in the pre-operative informed consent process.

\section{Abbreviation}

AMA: American Medical Association.

\section{Acknowledgements}

The authors acknowledge Rocky Vista University, Department of Research \& Scholarly Activity, and Lynne Stephenson of the Frank Ritchel Ames Memorial Library for her resourcefulness and editorial contributions.

\section{Institutional review board statement}

Not applicable.

\section{Authors' contributions}

Conceptualization, methodology, writing —original draft preparation, K.D.S., J.H., A.N.; writing-editing, K.D.S., J.H., A.N.; figures, K.D.S., J.H.; supervision, A.N. All authors have read and agreed to the published version of the manuscript.

Funding

Not applicable.

Availability of data and materials

All data and materials were obtained using public databases and have been cited appropriately.

\section{Declarations}

Ethics approval and consent to participate

Not applicable.

\section{Consent for publication}

Not applicable.

\section{Competing interests}

The authors declare that they have no competing interests.

\section{Author details}

${ }^{1}$ College of Osteopathic Medicine, Rocky Vista University, Ivins, UT 84738, USA. ${ }^{2}$ Division of Clinical Medicine and Surgery, Rocky Vista University, UT 84738 Ivins, USA.

Received: 14 January 2022 Accepted: 19 February 2022

Published online: 05 March 2022 


\section{References}

1. Taylor RM. Ethical principles and concepts in medicine. Handb Clin Neurol. 2013;118:1-9.

2. Osuna E, Pérez-Carrión A, Pérez-Cárceles MD, Machado F. Perceptions of health professionals about the quality of communication and deliberation with the patient and its impact on the health decision-making process. J Public Health Res. 2018;7:1445.

3. Talevski J, Wong Shee A, Rasmussen B, Kemp G, Beauchamp A. Teachback: a systematic review of implementation and impacts. PLoS One. 2020;15:e0231350.

4. Agarwal R, Sands DZ, Schneider JD, Smaltz DH. Quantifying the economic impact of communication inefficiencies in U.S. Hospitals J Healthc Manag. 2010:55:265-82.

5. Bittner-Fagan H, Davis J, Savoy M. Improving patient safety: improving communication. FP Essent. 2017;463:27-33.

6. Fentiman IS. Communication with older breast cancer patients. Breast J. 2007;13:406-9.

7. Brédart A, Bouleuc C, Dolbeault S. Doctor-patient communication and satisfaction with care in oncology. Curr Opin Oncol. 2005;17:351-4.

8. Appelbaum PS, Lidz CW, Meisel A. Informed Consent: Legal Theory and Clinical Practice. Fair Lawn, NJ: Oxford University Press; 1987.

9. Manta CJ, Ortiz J, Moulton BW, Sonnad SS. From the patient perspective, consent forms fall short of providing information to guide decision mak ing. J Patient Saf. 2021;17:e149-54.

10. Bracaglia R, D'Ettorre M, Gentileschi S, Tambasco D. Was the surgeon a satisfactory informant? How to minimize room for claims. Aesthet Surg J. 2014;34:632-5

11. Budhiraja S. AMA Code of Medical Ethics' Opinions Related to Palliative Surgical Care. AMA J Ethics. 2021;23:E811-813.

12. Kadam RA. Informed consent process: a step further towards making it meaningful! Perspect Clin Res. 2017:8:107-12.

13. Department of Health (UK). Reference Guide to Consent for Examination or Treatment. London: Department of Health publications; 2001. Available at http://www.dh.gov.uk/PolicyAndGuidance/HealthAndSocialCareT opics/Consent/Consent.

14. Schenker Y, Meisel A. Informed consent in clinical care: practical considerations in the effort to achieve ethical goals. JAMA. 2011:305:1130-1.

15. Schillinger D, Piette J, Grumbach K, Wang F, Wilson C, Daher C, et al. Closing the loop: physician communication with diabetic patients who have low health literacy. Arch Intern Med. 2003;163:83-90.

16. Green JA, Gonzaga AM, Cohen ED, Spagnoletti CL. Addressing health literacy through clear health communication: a training program for internal medicine residents. Patient Educ Couns. 2014:95:76-82.

17. Brega AG, Freedman MAG, LeBlanc WG, Barnard J, Mabachi NM, Cifuentes $M$, et al. Using the Health Literacy Universal Precautions Toolkit to Improve the Quality of Patient Materials. J Health Commun. 2015;20 Suppl 2:69-76.

18. Shersher V, Haines TP, Sturgiss L, Weller C, Williams C. Definitions and use of the teach-back method in healthcare consultations with patients: a systematic review and thematic synthesis. Patient Educ Couns. 2021;104:118-29.

19. Waszak DL, Mitchell AM, Ren D, Fennimore LA. A quality improvement project to improve education provided by nurses to ED patients prescribed opioid analgesics at discharge. J Emerg Nurs. 2018;44:336-44.

20. Bates OL, O'Connor N, Dunn D, Hasenau SM. Applying STAAR interventions in incremental bundles: improving post-CABG surgical patient care. Worldviews Evid-Based Nurs. 2014;11:89-97.

21. Ha Dinh TT, Bonner A, Clark R, Ramsbotham J, Hines S. The effectiveness of the teach-back method on adherence and self-management in health education for people with chronic disease: a systematic review. JBI Database Syst Rev Implement Rep. 2016;14:210-47.

22. Samuels-Kalow M, Hardy E, Rhodes K, Mollen C. "Like a dialogue": teachback in the emergency department. Patient Educ Couns. 2016;99:549-54.

23. Trivedi SP, Kopp Z, Tang AJ, Mammen A, Pandya D, Horwitz LI, et al. Discharge Communication: A Multi-Institutional Survey of Internal Medicine Residents' Education and Practices. Acad Med J Assoc Am Med Coll. 2021:96:1043-9.
24. Feinberg I, Ogrodnick MM, Hendrick RC, Bates K, Johnson K, Wang B. Perception versus reality: the use of teach-Back by medical residents. HLRP Health Lit Res Pract. 2019:3:e117-26.

25. Howard T, Jacobson KL, Kripalani S. Doctor talk: physicians' use of clear verbal communication. J Health Commun. 2013;18:991-1001.

26. D'Souza RS, Johnson RL, Bettini L, Schulte PJ, Burkle C. Room for improvement: a systematic review and Meta-analysis on the informed consent process for emergency surgery. Mayo Clin Proc. 2019;94:1786-98.

27. Schenker Y, Wang F, Selig SJ, Ng R, Fernandez A. The impact of language barriers on documentation of informed consent at a hospital with on-site interpreter services. J Gen Intern Med. 2007;22(Suppl 2):294-9.

28. Kim H, Song M-K. Medical decision-making for adults who lack decisionmaking capacity and a surrogate: state of the science. Am J Hosp Palliat Care. 2018;35:1227-34

29. Cocanour CS. Informed consent-It's more than a signature on a piece of paper. Am J Surg. 2017;214:993-7.

30. Hooker WART. XXIII.--physician and patient; or, a practical view of the mutual duties, relations, and interests of the medical profession and the community. Am J Med Sci. 1850;37:178.

31. Mohr v. Williams, 95 Minn. 261, 104 N.W. 12, 108 N.W. 818 (1905).

32. Pratt v. Davis, 224 III. 300, 79 N.E. 562 (1906).

33. Rolator v. Strain, 39 OK 572, 137 (1913).

34. Schloendorff v. Society of New York Hospital, 104 N.E. 92, 211 N.Y. 125 (1914).

35. Salgo v. Leland Stanford Jr. Univ. Bd. Trustees. 154 Cal. App. 2d 560, 317 P.2d 170 (1957).

36. 23. Natanson v. Kline, 186 Kan. 393, 411, 350 P. 2d 1093 (1960).

37. Cobbs v. Grant, 8 Cal.3d 229 (1972).

38. Wilkinson v. Vesey, 295 A.2d 676, 688 (R.I. 1972).

39. Truman v. Thomas, 27 Cal.3d 285 (1980).

40. Black's Law Dictionary, 9th ed, Garner BA (Ed), West Group, St. Paul, MN 2009.

41. 25 Tex Admin Code $\$ 601.2$ (2011).

42. Duttry v. Patterson, 771 A.2d 1255 (PA 2001).

43. Howard v. Univ. of Med. \& Dentistry of NJ, 800 A.2d 73,83 (NJ 2002).

44. Moore v. Regents of the University of California, 793 P.2d 479, 483 (Cal 1990).

45. Murphy v. Implicito, 920 A.2d 678 (N.J.Super.App., 2007).

46. Smith HK, Manjaly JG, Yousri T, Upadhyay N, Taylor H, Nicol SG, et al. Informed consent in trauma: does written information improve patient recall of risks? A prospective randomized study. Injury. 2012:43:1534-8.

47. Smith HK, Manjaly JG, Yousri T, Upadhyay N, Taylor H, Nicol SG, et al. Informed consent in trauma: does written information improve patient recall of risks? A prospective randomised study. Injury. 2012;43:1534-8.

48. Kinnersley P, Phillips K, Savage K, Kelly MJ, Farrell E, Morgan B, et al. Interventions to promote informed consent for patients undergoing surgical and other invasive healthcare procedures. Cochrane Database Syst Rev. 2013;CD009445.

49. Borello A, Ferrarese A, Passera R, Surace A, Marola S, Buccelli C, et al. Use of a simplified consent form to facilitate patient understanding of informed consent for laparoscopic cholecystectomy. Open Med Wars Pol. 2016:11:564-73.

50. Jamison v. Kilgore, 905 So. 2 d 610 (Miss. Ct. App. 2004)

51. Panea v. Isdaner, 773 A.2d 782 (2001).

52. Shinal v. Toms, 162 A.3d 429 (Pa. 2017)

53. Goss v. Oklahoma Blood Institute, 856 P.2d 998 (1990).

54. Klingbeil C, Gibson C. The teach-Back project: a system-wide evidencebased practice implementation. J Pediatr Nurs. 2018;42:81-5.

55. White M, Garbez R, Carroll M, Brinker E, Howie-Esquivel J. Is "teach-back" associated with knowledge retention and hospital readmission in hospitalized heart failure patients? J Cardiovasc Nurs. 2013;28:137-46.

56. Rahmani A, Vahedian-Azimi A, Sirati-Nir M, Norouzadeh R, Rozdar H, Sahebkar A. The effect of the teach-Back method on knowledge, performance, readmission, and quality of life in heart failure patients. Cardiol Res Pract. 2020;2020:8897881.

57. Yen PH, Leasure AR. Use and effectiveness of the teach-Back method in patient education and health outcomes. Fed Pract Health Care Prof. 2019;36:284-9.

58. Ryan-Madonna M, Levin RF, Lauder B. Effectiveness of the teachBack method for improving caregivers' confidence in caring for hospice patients and decreasing hospitalizations. J Hosp Palliat Nurs. 2019;21:61-70 
59. Choi S, Choi J. Effects of the teach-back method among cancer patients: a systematic review of the literature. Support Care Cancer. 2021;29:7259-68.

60. Zavala S, Shaffer C. Do patients understand discharge instructions? Emerg Nurs. 2011;37:138-40.

61. Engel $\mathrm{KG}$, Heisler M, Smith DM, Robinson CH, Forman JH, Ubel PA. Patient comprehension of emergency department care and instructions: are patients aware of when they do not understand? Ann Emerg Med. 2009;53:454-461.e15.

62. Oh EG, Lee HJ, Yang YL, Kim YM. Effectiveness of discharge education with the teach-Back method on 30-day readmission: a systematic review. J Patient Saf. 2021;17:305-10.

63. Slater BA, Huang $Y$, Dalawari P. The impact of teach-Back method on retention of key domains of emergency department discharge instructions. J Emerg Med. 2017;53:e59-65.

64. Glaser J, Nouri S, Fernandez A, Sudore RL, Schillinger D, Klein-Fedyshin M, et al. Interventions to improve patient comprehension in informed consent for medical and surgical procedures: an updated systematic review. Med Decis Mak. 2020;40:119-43.

65. Kesänen J, Leino-Kilpi H, Lund T, Montin L, Puukka P, Valkeapää K. The knowledge test feedback intervention (KTFI) increases knowledge level of spinal stenosis patients before operation-a randomized controlled follow-up trial. Patient Educ Couns. 2016;99:1984-91.

66. Fink AS, Prochazka AV, Henderson WG, Bartenfeld D, Nyirenda C, Webb $A$, et al. Enhancement of surgical informed consent by addition of repeat back: a multicenter, randomized controlled clinical trial. Ann Surg. 2010;252:27-36.

67. Prochazka AV, Fink AS, Bartenfeld D, Henderson WG, Nyirenda C, Webb A, et al. Patient perceptions of surgical informed consent: is repeat back helpful or harmful? J Patient Saf. 2014;10:140-5.

68. Wong AL, Martin J, Tang D, LeBlanc M, Morris SF, Paletz J, et al. The effect of written information on recall of surgical risks of carpal tunnel release surgery: a randomized controlled study. Plast Reconstr Surg. 2016;138:1011e-8e.

69. Egekeze N, Dubin J, Williams K, Bernhardt M. The age of Ortholnfo: a randomized controlled trial evaluating patient comprehension of informed consent. J Bone Joint Surg Am. 2016;98:e81.

70. Bethune A, Davila-Foyo M, Valli M, da Costa L. E-consent: approaching surgical consent with mobile technology. Can J Surg. 2018;61:339-44.

71. Kostick KM, Bruce CR, Minard CG, Volk RJ, Civitello A, Krim SR, et al. A multisite randomized controlled trial of a patient-centered ventricular assist device decision aid (VADDA trial). J Card Fail. 2018;24:661-71.

\section{Publisher's Note}

Springer Nature remains neutral with regard to jurisdictional claims in published maps and institutional affiliations.

Ready to submit your research? Choose BMC and benefit from:

- fast, convenient online submission

- thorough peer review by experienced researchers in your field

- rapid publication on acceptance

- support for research data, including large and complex data types

- gold Open Access which fosters wider collaboration and increased citations

- maximum visibility for your research: over 100M website views per year

At BMC, research is always in progress.

Learn more biomedcentral.com/submissions 